\title{
Anemia and Hematologic Characteristics in Newly Diagnosed Pulmonary Tuberculosis Patients at Diagnosis in Kinshasa
}

\author{
Christophe Mbombo Mulenga, Jean-Marie Ntumba Kayembe*, Benoit Obel Kabengele, \\ Alain Bakebe
}

Division of Pulmonology, University Hospitals of the University of Kinshasa, Faculty of Medicine, University of Kinshasa, Kinshasa, DR Congo

Email: *dr12jmkayembe@yahoo.com

How to cite this paper: Mulenga, C.M., Kayembe, J.-M.N., Kabengele, B.O. and Bakebe, A. (2017) Anemia and Hematologic Characteristics in Newly Diagnosed Pulmonary Tuberculosis Patients at Diagnosis in Kinshasa. Journal of Tuberculosis Research, 5, 243-257.

https://doi.org/10.4236/jtr.2017.54026

Received: August 26, 2017

Accepted: November 11, 2017

Published: November 14, 2017

Copyright $\odot 2017$ by authors and Scientific Research Publishing Inc. This work is licensed under the Creative Commons Attribution International License (CC BY 4.0).

http://creativecommons.org/licenses/by/4.0/

\begin{abstract}
Context. The burden of TB in Africa tends to be exacerbated by the socio-economic situation and the high prevalence of intercurrent infections such as HIV, malaria and non-specific bacterial infections. These factors often result in anemia, making patients at high risk for anemia. Objective: We aimed to gain insights into the characteristics of anemia, hematologic variations and socio-economic status in untreated pulmonary TB patients (PTB) in Kinshasa, the Democratic Republic of Congo. Methods. We conducted a cross-sectional analysis of 200 smear-positive pulmonary TB patients (PTB) recruited at the initiation of TB treatment. Complete Blood Count, Iron profile, BMI, CRP and albuminemia were assessed. Data were analyzed using Student $t$ or Mann Whitney tests as appropriate, and logistic regression was performed to assess the strength of associations. Results. Anemia was a regular finding in (69\%). This anemia was mostly moderate (92.2\%) and with iron deficiency pattern (48\%). Hypoalbuminemia was observed in half of the subjects and appears to be correlated with the severity of anemia. Surprisingly, the severity of inflammation, as reflected by the CRP, was inversely correlated with the anemia. In the multivariate analysis, alcohol intake (OR: 2.38; IC 95\%: 1.05 - 5.38), hypoalbuminemia (OR: 1.98; IC 95\%: 1.02 - 3.82) and CRP rate were significantly associated with the presence of anemia among pulmonary tuberculosis at the diagnostic. Conclusion: This study demonstrates the heavy burden of the iron responsive anemia and risky life conditions in newly diagnosed TB patients, and underscores the potential usefulness of iron supplementation in the Congolese context.
\end{abstract}

\section{Keywords}

Tuberculosis, Pulmonary Tuberculosis, Anemia Characteristics, Blood Cell 


\section{Introduction}

More than 130 years after the identification of Mycobacterium tuberculosis and 60 years after the first discovery of anti-tuberculous antibiotics, tuberculosis (TB) remains a public health concern, especially in developing countries. TB is still a major cause of mortality in the world, after HIV/AIDS. The World Health Organization reported an estimate of 1.4 million TB deaths for 2015 [1]. Unsurprisingly, the greatest majority of deaths occurred in sub-Saharan Africa and South Asia [1]. The Democratic Republic of the Congo is one of the top 22 by estimated absolute number of TB cases, and the 5th in Africa. The incidence of TB in DRC was estimated to 250,000 new cases in 2015 [1]. The burden of TB in this country seems to be exacerbated by the difficult socio-economic situation and the high prevalence of some intercurrent infections such as HIV, malaria and non-specific bacterial infections. In addition, Sickle Cell Anemia (SCA), a chronic hemolytic anemia, is particularly highly prevalent in DRC and co-morbidity TB-SCA can be expected in this country as reported elsewhere [2] [3]. Each of these factors often results in anemia among other complications, making the Congolese population one at high risk for anemia of various origins.

Anemia is widely recognized as a common TB-associated morbidity [4] [5]. The prevalence of TB-associated anemia varies from $32 \%$ to $86 \%$ [5] [6] [7] and numerous causes have been invoked [8]. It should be noted that anemia in tuberculosis is mainly inflammatory anemia (anemia of inflammation or AI). Interestingly, this AI often resolves with $\mathrm{TB}$ treatment as previously reported [4] [5] [9]. Also, depending on whether HIV is also present or not, resolution of anemia was reported after ART treatment in TB-HIV+ patients [10]. Of interest, patients with iron-responsive anemia (iron deficiency anemia (IDA), and multifactorial anemia (IDA + AI)) [4] [9] do not show spontaneous resolution of anemia with TB treatment. Rather, iron-responsive anemia in TB tends to recover quickly after 2 or 3 months of iron supplement in addition to TB treatment [4] [11]. Based on the observation that anemia is generally multifactorial in Sub-Saharan Africa (SSA) [8], it can be speculated that majority of TB-patients would need iron supplement. Caution is however warranted since iron-based intervention is not only unnecessary in $\mathrm{AI}$, but can also cause iron overloading and be harmful, e.g. by increasing bacterial replication through shifting of Th1 to Th2 cytokine responses, and blocking the No-dependent bactericidal activity [4] [12]. Therefore, iron status biomarkers are important in determining the real need and efficiency for iron supplement.

Besides iron assessment, a full characterization of anemia should be recommended since other hematologic modifications affecting platelets, leucocytes or proteins can inform about the disease prognostic. Results from leucocytes and platelet lineages assessment in TB are variable in that both leukocytosis and 
leukopenia are reported, as well as both thrombocytosis and thrombocytopenia [6]. Besides, hypoalbuminemia, which is tightly associated with nutrition deficiency in this setting, has also been recognized to influence the TB prognostic [13] [14] [15]. The meaning of these variations with regards to the anemia seems unclear.

A better understanding of the causes and types of TB-associated variations would pave the way for the implementation of efficient management strategies in DRC. This study aimed at gaining insights into the characteristics of anemia, hematologic variations and socio-economic status in untreated pulmonary TB patients (PTB) in Kinshasa, the Democratic Republic of Congo.

\section{Methods}

\subsection{Study Design and Population}

This study was conducted in 5 centers fully dedicated to the diagnostic and treatment of TB in Kinshasa (DTC) between June and October 2015. These DTC were selected based on their geographical accessibility and the high number of treated patients. In each of these centers, we systematically recruited all adult TB patients (aged at least 15 years) newly diagnosed and naïve of any TB treatment. The diagnostic was considered positive upon the detection of acid fast bacilli (AFB) on 2 consecutive sputum smears stained by Ziehl-Neelsen. In addition to patients previously under TB treatment, we also excluded patients with comorbidities (a disease with significant impact of hematologic parameters) or other treatment with potential impact on hematological parameters, with exception for HIV. HIV screening was performed on whole blood sample. A total of 200 patients were recruited and from each of them we collected anamnestic (previous exposure contact, alcohol and/or tobacco use), demographic information (age, sex, gender) and anthropometric data (weight and height for BMI calculation). The time interval between the onset of symptoms and diagnosis of tuberculosis, and the social and economic level (SEL) according to the scale of the Ministry of plan in DR Congo, were also recorded.

\subsection{Laboratory Procedures}

Blood sample was drawn from each participant both in a dry tube and in an EDTA coated tube, and these tubes were transported in a cool box to the laboratories. The complete blood count was performed at the Monkole Hospital using the sample in the coated tube on a Sysmex XN-1000 PLC sysmex corporation japan Kobe 2012), within 6 hours after the collection, and following the manufacturer's procedure. This PLC delivered the hemoglobin ( $\mathrm{Hb}$ ) level and hematocrit $(\mathrm{Ht})$, white blood cell total and differential counts, platelets and red blood cell counts, as well as the reticulocyte count.

Conversely, the dry tube was centrifuged at $5000 \mathrm{rpm}$ on a KOKUSAN H-36 centrifuge (Kokusan corporation japan Tokyo) and the plasma was collected and stored at $-20^{\circ} \mathrm{C}$ for the following analyzes: C-Reactive Protein (CRP, $\mathrm{mg} / \mathrm{l}$ ), albu$\min (\mu \mathrm{g} / \mathrm{l})$, iron $(\mathrm{g} / \mathrm{dl})$, transferrin $(\mathrm{mg} / \mathrm{dl})$, creatinine $(\mathrm{mg} / \mathrm{dl})$, and HIV serology. 
The dry tube was transferred upon collection to the University Hospitals of the University of Kinshasa (CUK) where serum iron was assayed by spectrophotometry as previously described [16].

The measurement of serum albumin was done at the CUK on a photometric colorimetric test based on the previously described principals [17], using the Albumin liquicolor kit $^{\oplus}$ (Human $\mathrm{GmbH}$, Germany) and following the manufacturer procedure (HUMAN, Wiesbaden, Germany). In this procedure, the bromocresol green is mixed with albumin in a citrate buffer and created a unit that has an absorbance that is proportional to the concentration of serum albumin. The CRP was quantitatively estimated using Humatex CRP kit (Human GmbH, Germany) according to the manufacturer's protocol. It should be noted that the serum transferrin and creatinine were assayed only in the 62 patients with the lowest hemoglobin level (5.8 to $10.6 \mathrm{~g} / \mathrm{dL}$ ). The kit transferring and calibrator C3 C4 TRF Standard (Human GmbH, Germany) was used for transferrin quantification and the absorbance was read at wavelength of $340 \mathrm{~nm}$ on a Human lyser primus (Human GmbH, Germany) XXX (Firme, Ville), based on a turbidimetric method. The dosage of serum creatinine was based on the Jaffé reaction [18].

\subsection{Operational Definitions}

The socioeconomic level was evaluated by scoring the assets in the household and the accommodation characteristics, and the classification was made based on the total score:

- Low socioeconomic level, when the score is $\leq 5$.

- Average socioeconomic level, when the score is between 5 and 11.

- High socioeconomic level, when the score is above 10 [19].

Undernutrition was defined as a $\mathrm{BMI}<18.5 \mathrm{~kg} / \mathrm{m}^{2}[20]$.

Anemia was defined as $\mathrm{Hb}>13 \mathrm{~g} / \mathrm{dl}$ for men or $\mathrm{Hb}<12 \mathrm{~g} / \mathrm{dl}$ for women [21].

Based on the hemoglobin, the anemia was classified as [22]

- moderate between 8 - $12 \mathrm{~g} / \mathrm{dl}$ (for women) and 8 - $13 \mathrm{~g} / \mathrm{dl}$ (for men)

- severe below $8 \mathrm{~g} / \mathrm{dl}$

The microcytic Anemia was defined by a value of VGM $<80 \mu^{3}$, the macrocytic anemia by a value of MCV $>100 \mu^{3}$, and the hypochromic anemia by a value of MCHC less than 32\% [22]. Iron deficiency anemia in case of inflammation is defined by an elevated CRP (greater than 6), anemia and elevated serum transferrin (greater than $340 \mathrm{mg} / \mathrm{dl}$ reference value according to the manufacturer) [23]. Leukopenia was defined as a value of WBC less than 4000 elements per $\mathrm{mm}^{3}$, leukocytosis by WBC count above $10,000 / \mathrm{mm}^{3}$ [24], thrombocytopenia as a platelet count below $150,000 / \mathrm{mm}^{3}$ [25], thrombocytosis as platelet counts greater than 400,000 cells $/ \mathrm{mm}^{3}$ [25]. The smear-positive Pulmonary TB was confirmed when at least two Ziehl tests on three sputum specimens were positive, or in case of a single positive Ziehl test on three specimens associated with a radiological image compatible with active tuberculosis; or a single positive Ziehl test on three samples in the context of HIV seropositive. 


\subsection{Statistical Analysis}

We used Microsoft Excel 2010 and SPSS version 21.0 to store and compute our data. Tables or graphics were used, as appropriate, for the presentation of results. Continuous quantitative variables with Gaussian distribution were expressed as mean \pm standard deviation, whereas those with abnormal distribution were presented as median (extremes). Qualitative variables were described as relative frequency (\%). Comparison of means or medians of two groups was made, as appropriate, using the Student $t$ test or Mann Whitney U test. One-way ANOVA test was used to compare the means of more than 2 groups, the Pearson chi-square test or Fisher exact test was used to compare proportions. Factors associated with the blood count disorder were sought through logistic regression, odds ratio and $95 \%$ confidence intervals were shown. For all statistical tests the level of significance was $\mathrm{p}<5 \%$.

\subsection{Ethical Considerations}

This study was conducted with the approval of the National Tuberculosis Program. Oral consent was obtained after oral explanation of the study aims and methods. The confidentiality was guaranteed by De-anonymizing data. The results were returned to those patients after appropriate counselling.

\section{Results}

\subsection{General Characteristics of the Study Population}

The general characteristics of the study population are summarized in Table 1.

The mean age was 30.1 years for the 200 patients, and there were more males (65\%) than females. Married and single represented respectively $34 \%$ and $58.5 \%$. The vast majority of our patients $(80 \%)$ received at least the secondary school education and $19 \%$ were pursuing their studies at the time of recruitment. However, $40 \%$ were unemployed. About $93 \%$ had a low socioeconomic level.

Regarding patient's lifestyle and history, $29 \%$ were alcohol consumers while $27.5 \%$ were current smokers. Previous contact with TB patients was reported in $16 \%$ of cases and $6.5 \%$ had a positive HIV status. Half of patients were malnourished (51\%) and the median duration of the disease since diagnostic was 4 weeks. About $58 \%$ of patients presented with hypoalbuminemia and the median CRP was $24 \mathrm{mg} / \mathrm{dl}$.

With respect to the thresholds applied during this study, anemia was present in 139/200 subjects (69.5\%). The characteristics of anemia are shown in details in Table 2. The common form was moderate regenerative anemia. Iron deficiency was observed in about half of the cohort as suggested by the RBC indices.

\subsection{Anemia and Serum Transferrin}

Serum transferrin assessed in 62 patients presenting with the lowest $\mathrm{Hb}$ values ( $\leq 5.8$ to $10.6 \mathrm{gr} / \%$ ) allowed the distinction of two groups: the first group had anemia associated with low or normal serum transferrin values $(48.4 \%)$ whereas 
Table 1. General characteristics of the study population.

\begin{tabular}{ccc}
\hline \multicolumn{1}{c}{ Variables } & $\mathbf{N}=\mathbf{2 0 0}$ & $\%$ \\
\hline Age, means \pm SD, years & $30.1 \pm 11.8$ & \\
Gender & & 65.0 \\
Male & 130 & 35.0 \\
Female & 70 & \\
Profession & & 39.5 \\
Unemployed & 79 & 32.0 \\
Independent & 64 & 19.0 \\
Student & 38 & 5.5 \\
Driver & 11 & 4.0 \\
Stateworker & 8 &
\end{tabular}

\section{Marital status}

$\begin{array}{lcc}\text { Single } & 117 & 58.5 \\ \text { Married } & 68 & 34.0 \\ \text { Divorced } & 9 & 4.5 \\ \text { Widow(ed) } & 6 & 3.0\end{array}$

Education

$\begin{array}{lcc}\text { None } & 2 & 1.0 \\ \text { Primary } & 38 & 19.0 \\ \text { Secondary or higher } & 160 & 80.0\end{array}$

SES

$\begin{array}{lll}\text { Low } & 185 & 92.5\end{array}$

$\begin{array}{lll}\text { Middle } & 14 & 7.0\end{array}$

High $\quad 1 \quad 0.5$

$\begin{array}{lrr}\text { Alcohol intake } & 58 & 29.0\end{array}$

Tobacco

$55 \quad 27.5$

Median disease duration (Q1-Q3), in weeks

$4(3-6)$

History of tuberculosis $\quad 32$

16.0

HIV status

13

6.5

BMI, mean $\pm \mathrm{SD},\left(\mathrm{kg} / \mathrm{m}^{2}\right)$

$18.0 \pm 2.4$

$$
\begin{aligned}
& \mathrm{BMI}<18.5 \\
& \mathrm{BMI} \geq 18.5
\end{aligned}
$$

98

49.0

Albumin

Hypoalbuminemia

Normal
115

85

$24(3.6-192)$

$\%$ 65.0 0 .5 .0 .0

5

0

8.5

5

.0


Table 2. Characteristics of anemia.

\begin{tabular}{lcc}
\hline \multicolumn{1}{c}{ Variables } & $\mathbf{n}$ & $\%$ \\
\hline Severity & 131 & 92.2 \\
Moderate & 8 & 5.8 \\
$\quad$ Severe & & \\
Central or peripheral & 119 & 92.2 \\
$\quad$ Regenerative & 10 & 7.8 \\
Non regenerative & & \\
RBC mean volume and Hb concentration & 73 & 52.5 \\
Hypochromic microcytic & 66 & 47.5 \\
Hypochromic normocytic & & \\
\hline
\end{tabular}

RBC: Red blood cells.

the second had anemia with high serum transferrin values (51.6\%). Iron deficiency anemia suggested by a high serum transferrin is present in slightly more than 1 out of 2 patients.

Normal or low transferrin was significantly associated with inflammation expressed by CRP rate $(\mathrm{p}=0.024)$ in the sub-cohort of 62 patients (Table 3 ).

The cell count in white lineage was within the normal range in the vast majority of patients (80\%), whereas hyperleukocytosis was observed in $11 \%$ and leukopenia in only $9 \%$ (Figure 1 ).

The platelet count was normal in $65.5 \%$ of cases, and thrombocytosis or thrombocytopenia was observed respectively in $25.5 \%$ and $8 \%$ of subjects (Figure 2).

Table 4 shows factors associated with the presence of anemia. Alcohol consumption, HIV positive status and hypoalbuminemia were risk factors for anemia.

Anemia was more frequent in the hypo-albuminemia context. Hypo-albuminemia was twice more associated with anemia than normo albuminemia (OR: 1.98; IC 95\%: 1.02 - 3.82). The CRP was more elevated in patient with anemia (36.4 vs 24.4$)$.

\section{Discussion}

In this study, we prospectively recruited newly diagnosed PTB patients from treatment centers across Kinshasa and investigated their general characteristics, anemia as well as other hematologic changes. The mean age of patients was around 30 years and male patients were predominant in this study. Similar trend has been previously reported from the Sub-Saharan Africa sub-continent and elsewhere [4] [5] [6]. This predominance of male patients within their active age supports the previous assumption that the disease mainly affects young people with great mobility. In addition, smoking and alcohol intake are important risk factors frequently observed in this age and gender category, as previously reported [26] [27]. Likewise, nearly one in three patients in the current study has a 
Table 3. Transferrin level and biological profiles.

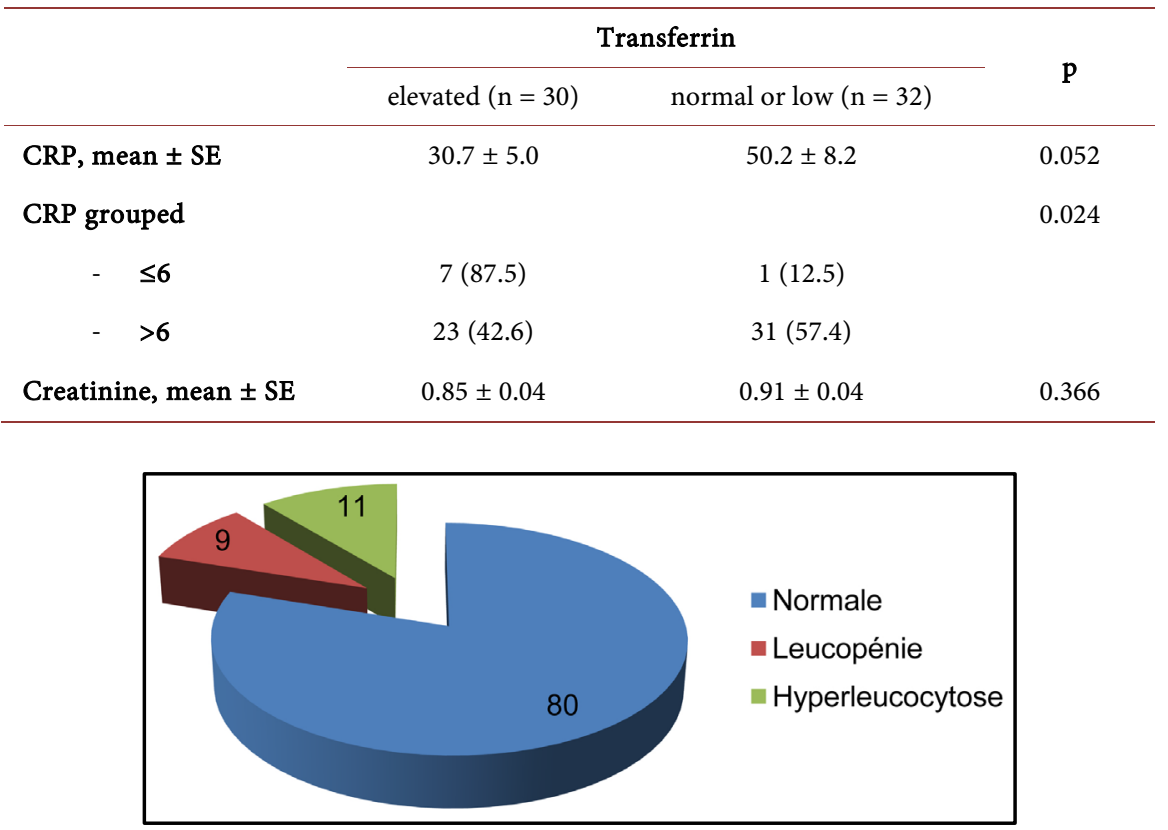

Figure 1. Disorders in the white lineage.

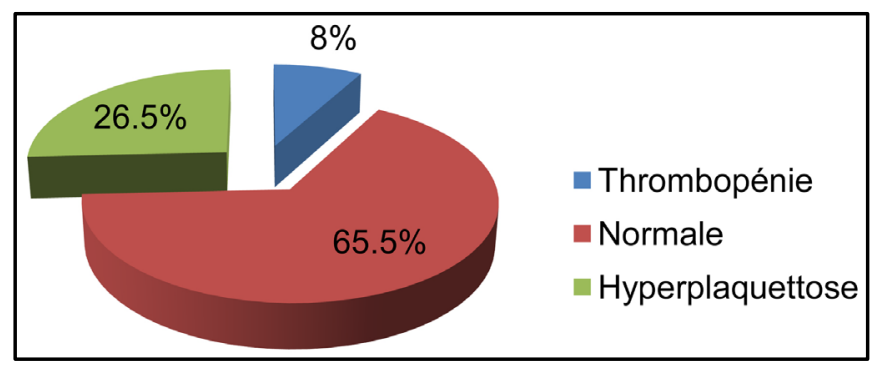

Figure 2. Frequency of thrombocyte lineage abnormalities.

history of smoking and alcohol intake.

There is a surprising contrast between the higher number of patients with at least secondary education (80\%) and the particularly high number of patients with low socio-economic situation (SES) (92.5\%). The higher education rate is compatible with the urban setting where this study was conducted. In contrary, the lower SES overserved here supports the known correlation between TB and poverty [28].

Half of patients presented with BMI below 18.5 and hypoalbuminemia, which corresponds to undernutrition. Such observation is not a surprisingin TB patients given the anorexia, the TNF- $\alpha$ related cachexia and other factors. TNF- $\alpha$ is abundantly produced during the macrophage invasion of bacilli [29] [30]. In addition, the underprivileged live related to the SES can also be seen as potential contributor to the low BMI.

The $6.5 \%$ rate of TB-HIV/AIDS co-infection in this study is significantly lower than the 15\% DRC average or 31 African average reported in the WHO Global report 2016 [1], and strikingly low than the $76 \%$ reported in Kenya [31]. The 
Table 4. Factors associated with presence of anemia.

\begin{tabular}{|c|c|c|c|c|c|c|}
\hline & \multicolumn{2}{|c|}{ Anemia } & \multirow{2}{*}{ Crude OR brut (IC 95\%) } & \multirow{2}{*}{$\mathrm{p}$} & \multirow{2}{*}{ adjusted OR (IC 95\%) } & \multirow{2}{*}{$\mathrm{p}$} \\
\hline & yes $(n=139)$ & no $(n=61)$ & & & & \\
\hline Age, mean $\pm S E$ & $30.4 \pm 0.9$ & $29.5 \pm 1.5$ & $1.01(0.98-1.03)$ & 0.617 & $1.00(0.97-1.03)$ & 0.906 \\
\hline \multicolumn{7}{|l|}{ Gender } \\
\hline - Female & $49(70.0)$ & $21(30.0)$ & $1.04(0.55-1.95)$ & 0.91 & $1.45(0.72-2.94)$ & 0.303 \\
\hline - Male & $90(69.2)$ & $40(30.8)$ & 1 & & 1 & \\
\hline \multicolumn{7}{|l|}{ Alcohol } \\
\hline - yes & $47(81.0)$ & $11(19.0)$ & $2.32(1.11-4.87)$ & 0.026 & $2.38(1.05-5.38)$ & 0.037 \\
\hline- no & $92(64.8)$ & $50(35.2)$ & 1 & & & \\
\hline \multicolumn{7}{|l|}{ HIV status } \\
\hline - yes & $11(84.6)$ & $2(15.4)$ & $2.54(0.55-11.80)$ & 0.236 & $2.26(0.45-11.36)$ & 0.321 \\
\hline- no & $128(68.4)$ & $59(31.6)$ & 1 & & 1 & \\
\hline \multicolumn{7}{|c|}{$\begin{array}{l}\text { Hypoalbuminemia } \\
\text { albuminemia }\end{array}$} \\
\hline - yes & $90(78.3)$ & $25(21.7)$ & $2.65(1.43-4.91)$ & 0.002 & $1.98(1.02-3.82)$ & 0.042 \\
\hline- no & $49(57.6)$ & $36(42.4)$ & 1 & & 1 & \\
\hline $\mathrm{CRP}$, mean $\pm \mathrm{SE}$ & $36.4 \pm 2.7$ & $24.4 \pm 2.2$ & $1.02(1.01-1.04)$ & 0.007 & $1.02(1.00-1.03)$ & 0.029 \\
\hline
\end{tabular}

SE: Standard error.

disparity could result from differences in study design and setting. It has been abundantly proven that many TB-HIV patients present with smear-negative or extra pulmonary TB [32] [33] [34] [35]. The fact that the current study only included smear-positive Pulmonary TB patients, and that extra-pulmonary TB was not considered could have resulted in a significant exclusion of TB-HIV patients, thus leading to lower TB-HIV rate.

Anemia of any severity was observed in more than two-third of patients (69.5\%) in the current study. This is rather a common finding during TB [4] [5], with significant frequency variability, including $67 \%$ in Gambia, $63.2 \%$ in Indonesia, 37\% in Ethiopia [7], or 31.9\% in South Korea [4] [5] [9]. However, the anemia in the current study seems to be at the upper end of the reported frequencies. This could be due to the high burden of iron deficiency reported here. Of note, iron deficiency was diagnosed in about half of patients with moderate to severe anemia. This is significantly higher than in previous studies where anemia of inflammation was significantly the most common form in TB patients [4]. It can be speculated, based on the low BMI and hypoalbuminemia, that unbalanced or insufficient nutrition partly explains the iron deficiency identified in the current study. Considering that iron supplementation in mild to moderate PTB-associated anemia previously showed increased Fe saturation of transferrin [11], we recommend systematic assessment, wherever it is possible, of iron profile, and subsequent iron supplementation at early stage of TB treatment in PTB patients with iron-responsive anemia in Kinshasa. The multifactorial nature of 
anemia is not easy to establish in Congolese setting and was not assessed here. However, it should be noted that the mean CRP $(24 \mathrm{mg} / \mathrm{dL})$ reported is this study is significantly higher than in many other studies. Based on previous studies, such high CRP values are suggestive for community acquired pneumonia (CAP) rather than TB alone where CRP values were often below $10 \mathrm{mg} / \mathrm{dL}$ [36] [37]. Therefore, it cannot be excluded that another infection could be superimposed to TB in some patients and exacerbate iron deficiency in the current study. Neither malaria, non-specific infections, nor SCD, known to be endemic in the Congolese setting, were specifically excluded as a potential cause for anemia in this study. The investigation of the consequence of anemia on the treatment outcome is beyond the scope of the current study.

Although majority of our patients have normal leucocyte count (80\%) and platelet count (65.5\%), some variations were observed included leukocytosis (11\%), leukopenia (9\%), thrombocytosis (25.5\%) and thrombocytopenia (8\%). Depending of studies, important variations of leukocytes, including leukocytosis in $3 \%$ to $28.63 \%$ and leucopenia in $2.20 \%$ to $24 \%$ of patients, have been previously reported [3] [6] [39]. It should be noted that these leucocytes variations were far from being evenly distributed. Leukopenia was most frequent in TB/HIV co-infection ( $\mathrm{p}=0.034)$ in this study as well as in the study by Hane et al. in Senegal [24]. The immune response in TB is still poorly understood [40] [41] [42]. The reported compartmentalization of immune response is a dynamic process and temporal changes in leucocytes and other blood immune markers have been reported [40]. This phenomenon probably contributes to variations observed from one study to another. In the current study, leucocyte variations were far from being evenly distributed. Leucopenia was most frequent in TB-HIV co-infection $(\mathrm{p}=0.034)$ as similarly reported by Hane et al. [24]. Thus, the impact of HIV on hematopoiesis is another plausible explanation for the leucocyte variations. On the other hand, platelet variations, more specially thrombocytosis, are common observations in tuberculosis. Thrombocytopenia in TB was ascribed to a general context of pancytopenia, a form of immune thrombocytopenia or to effect of anti-tuberculosis antibiotics [43] [44] [45]. The range of variations of platelet count observed in this study is close to previous reports [6]. Renshaw and Gould (2013) suggested that patients with thrombocytopenia and pulmonary infection had increased risk for positive mycobacterial culture [46]. This assumption was not specifically investigated in the current study. Instead, we observed an association between thrombocytopenia and alcohol consumption in the current study. It has been reported that chronic alcohol consumption results respectively in significant increase in the Mean Platelet Volume (MPV) and significant mean of platelet count [47]. However, we cannot objectively incriminate alcohol consumption in the platelet count variation in this study since chronic consumption as well as the severity of consumption was not assessed. Our result supports a correlation between CRP and MPV. This is consistent with previous observations [25] [48].

In univariate analysis, alcohol consumption, HIV infection, hypoalbuminemia 
and CRP showed a significant association with anemia in the study population. This association remained significant in multivariate analysis only for alcohol intake (OR: 2.38; IC 95\%: 1.05 - 5.38), hypoalbuminemia (OR: 1.98; IC 95\%: 1.02 - 3.82), with an inverse correlation for CRP rate. The link between alcohol consumption and TB was previously reported and could be attributed to the immunosuppressive role of alcohol [49] [50].

This is the first comprehensive study of hematologic variation in TB in Kinshasa. However, these results need to be interpreted with caution due to study limits, mostly attributable to the design of the study and to the limited resourced setting. The first one is inherent to the cross-sectional nature of the study and the small size of the sample which cannot allow generalization of data to the all population of Kinshasa. The second is the lack of validated reference values for blood counts related to race and socio-economic environment and the use of WHO recommended standards in this area. The third limitation is related to the semi-quantitative assay of CRP, which can introduce bias due to the visual assessment by a single individual. Main strengths are the assessment of anemia characteristic at TB diagnosis which can influence therapeutic strategies by the national TB program. Further studies will use these values to address longitudinal studies involving more patients.

\section{References}

[1] World Health Organization (2016) Global Tuberculosis Report 2016. WHO Library Cataloguing-in-Publication Data.

[2] Droz, N., De Lauzanne, A., Holvoet, L., Missud, F., Benkerrou, M., Brousse, V., Odièvre, M.H., Faye, A. and Koehl, B. (2017) Tuberculosis in Children with Sickle Cell Anaemia: A Retrospective Study in French Tertiary Care Centres. European Journal of Pediatrics, 176, 723-729.

[3] Ahmed, S.G., Bukar, A.A. and Jolayemi, B. (2010) Hematological Indices of Sickle Cell Anaemia Patients with Pulmonary Tuberculosis in Northern Nigeria. Mediterranean Journal of Hematology and Infectious Diseases, 2, e2010014.

[4] Minchella, P.A., Donkor, S., Owolabi, O., Sutherland, J.S. and McDermid, J.M. (2015) Complex Anemia in Tuberculosis: The Need to Consider Causes and Timing When Designing Interventions. Clinical Infectious Diseases, 60, 764-772.

[5] Lee, S.W., Kang, Y.A., Yoon, Y.S., Um, S.W., Lee, S.M., Yoo, C.G., Kim, Y.W., Han, S.K., Shim, Y.S. and Yim, J.J. (2006) The Prevalence and Evolution of Anemia Associated with Tuberculosis. Journal of Korean Medical Science, 21, 1028-1032. https://doi.org/10.3346/jkms.2006.21.6.1028

[6] Banerjee, M., Chaudhary, B.L. and Shukla, S. (2015) Hematological Profile among Pulmonary Tuberculosis Patients in Tertiary Care Hospital. International Journal of Bioassays, 4, 3900-3902.

[7] Atomsa, D., Abebe, G. and Sewunet, T. (2014) Immunological Markers and Hematological Parameters among Newly Diagnosed Tuberculosis Patients at Jimma University Specialized Hospital. Ethiopian Journal of Health Sciences, 24, 311-318. https://doi.org/10.4314/ejhs.v24i4.6

[8] Kassebaum, N.J., Jasrasaria, R., Naghavi, M., Wulf, S.K., Johns, N., Lozano, R., Regan, M., Weatherall, D., Chou, D.P., Eisele, T.P., Flaxman, S.R., Pullan, R.L., Brooker, 
S.J. and Murray, C.J. (2014) A Systematic Analysis of Global Anemia Burden from 1990 to 2010. Blood, 123, 615-624. https://doi.org/10.1182/blood-2013-06-508325

[9] Sahiratmadja, E., Wieringa, F.T., van Crevel, R., de Visser, A.W., Adnan, I., Alisjahbana, B., Slagboom, E., Marzuki, S., Ottenhoff, T.H., van de Vosse, E. and Marx, J.J. (2007) Iron Deficiency and NRAMP1 Polymorphisms (INT4, D543N and 3'UTR) Do Not Contribute to Severity of Anaemia in Tuberculosis in the Indonesian Population. British Journal of Nutrition, 98, 684-690. https://doi.org/10.1017/S0007114507742691

[10] Kerkhoff, A.D., Wood, R., Cobelens, F.G., Gupta-Wright, A., Bekker, L.G. and Lawn, S.D. (2014) Resolution of Anaemia in a Cohort of HIV-Infected Patients with a High Prevalence and Incidence of Tuberculosis Receiving Antiretroviral Therapy in South Africa. BMC Infectious Diseases, 14, 3860.

https://doi.org/10.1186/s12879-014-0702-1

[11] Devi, U., Rao, C.M., Srivastava, V.K., Rath, P.K. and Das, B.S. (2003) Effect of Iron Supplementation on Mild to Moderate Anaemia in pulmonary Tuberculosis. The British Journal of Nutrition, 90, 541-550. https://doi.org/10.1079/BJN2003936

[12] Weiss, G. (2002) Pathogenesis and Treatment of Anaemia of Chronic Disease. Blood Reviews, 16, 87-96. https://doi.org/10.1054/blre.2002.0193

[13] Borgdorff, M.W., Veen, J., Kalisvaart, N.A. and Nagelkerke, N. (1998) Mortality among Tuberculosis Patients in the Netherlands in the Period 1993-1995. European Respiratory Society, 11, 816-820. https://doi.org/10.1183/09031936.98.11040816

[14] Waitt, C.J. and Squire, S.B. (2011) Une revue systématique des facteurs de risque de décès chez les adultes pendant et après le traitement de la tuberculose. [A Systematic Review of Risk Factors for Death in Adults during and after Tuberculosis Treatment (Review Article).] International Journal of Tuberculosis and Lung Disease, 15, 871-885. http://www.theunion.org/journals/english/article/waitt2011juillp871fr.pdf https://doi.org/10.5588/ijtld.10.0352

[15] Matos, E.D. and Moreira Lemos, A.C. (2006) Association between Serum Albumin Levels and In-Hospital Deaths Due to Tuberculosis. International Journal of $\mathrm{Tu}$ berculosis and Lung Disease, 10, 1360-1366.

[16] Garcic, A. (1979) A Highly Sensitive, Simple Determination of Serum Iron Using Chromazurol B. Clinica Chimica Acta, 94, 115-119.

https://doi.org/10.1016/0009-8981(79)90003-2

[17] Doumas, B.T., Watson, W.A. and Biggs, H.G. (1997) Albumin Standards and the Measurement of Serum Albumin with Bromcresol Green. Clinica Chimica Acta, 258, 21-30. https://doi.org/10.1016/S0009-8981(96)06447-9

[18] Delanaye, P., Cavalier, E., Maillard, N., Krzesinski, J.M., Mariat, C., Cristol, J.P. and Piéroni, L. (2010) Creatinine: Past and Present. Annales De Biologie Clinique (Paris), 68, 531-543.

[19] Ministry of Planification, Ministry of Health and ICF International (2014) Demographic and Health Survey in DR Congo 2013-2014. MPSMRM, MSP et ICF International, Rockville, Maryland.

https://www.unicef.org/drcongo/french/00_-_00_-_DRC_DHS_2013-2014_FINAL_ PDF_09-29-2014.pdf

[20] World Health Organization (2017) BMI Classification. World Health Organization, Geneva. http://apps.who.int/bmi/index.jsp?introPage=intro_3.html

[21] World Health Organization (2008) WHO and the CDC Worldwide Prevalence of Anemia 1993-2005: Who Global Database on Anemia. World Health Organization, Geneva. 
[22] World Health Organisation (2011) Hemoglobin Concentrations for the Diagnosis of Anaemia and Assessment of Severity. World Health Organization, Geneva.

[23] Weiss, G. and Goodnough, L.T. (2005) Anemia of Chronic Disease. The New England Journal of Medicine, 35, 1011-1023. https://doi.org/10.1056/NEJMra041809

[24] Hane, A.A., Thiam, D., Cissokho, S., Kabou, F., Ndiaye, M., Diop, S., Ba, O., Fall, K., Diop, B.M., Ndir, M., Diedhiou, A., Touré-Fall, A.O. and Diakhate, L. (1999) Hematologic Abnormalities and Immunodepression in HIV/AIDS-Related Pulmonary Tuberculosis. Bulletin De La Societe De Pathologie Exotique, 92, 161-163.

[25] Unsal, E., Aksaray, S., Köksal, D. and Sipit, T. (2005) Potential Role of Interleukin 6 in Reactive Thrombocytosis and Acute Phase Response in Pulmonary Tuberculosis. Postgraduate Medical Journal, 81, 604-607. https://doi.org/10.1136/pgmj.2004.030544

[26] Oliva, V.M., Cezário, G.A.G., Cocato, R.A. and Marcondes-Machado J. (2008) Pulmonary Tuberculosis: Hematology, Serum Biochemistry and the Relation with the Disease Duration. Journal of Venomous Animals and Toxins Including Tropical Diseases, 14, 71-81. https://doi.org/10.1590/S1678-91992008000100006

[27] Blanc, F.-X. (2011) Tuberculose: Le réveil d'une belle endormie. [Tuberculosis: Waking up from a Deep.] Revue des Maladies Respiratoires Actualités, 3, 532-537. https://doi.org/10.1016/S1877-1203(11)70165-3

[28] Pelissari, D.M. and Diaz-Quijano, F.A. (2017) Household Crowding as a Potential Mediator of Socioeconomic Determinants of Tuberculosis Incidence in Brazil. PLoS $O N E, 12$, e0176116. https://doi.org/10.1371/journal.pone.0176116

[29] Abebe, F., Belay, M., Legesse, M., Mihret, A. and Franken, K.S. (2017) Association of ESAT-6/CFP-10-Induced IFN- $\gamma$, TNF- $\alpha$ and IL-10 with Clinical Tuberculosis: Evidence from Cohorts of Pulmonary Tuberculosis Patients, Household Contacts and Community Controls in an Endemic Setting. Clinical \& Experimental Immunology, 189, 241-249. https://doi.org/10.1111/cei.12972

[30] Kellar, K.L., Gehrke, J., Weis, S.E., Mahmutovic-Mayhew, A., Davila, B., Zajdowicz, M.J., Scarborough, R., LoBue, P.A., Lardizabal, A.A., Daley, C.L., Reves, R.R., Bernardo, J., Campbell, B.H., Whitworth, W.C. and Mazurek, G.H. (2011) Multiple Cytokines Are Released When Blood from Patients with Tuberculosis Is Stimulated with Mycobacterium tuberculosis Antigens. PLoS One, 6, e26545.

https://doi.org/10.1371/journal.pone.0026545

[31] Nyamogoba, H.D., Mbuthia, G., Mining, S., Kikuvi, G., Biegon, R., Mpoke, S., Menya, D. and Waiyaki, P.G. (2012) HIV Co-Infection with Tuberculous and Non-Tuberculous Mycobacteria in Western Kenya: Challenges in the Diagnosis and Management. African Health Sciences, 12, 305-311.

[32] Saranchuk, P., Boulle, A., Hilderbrand, K., Coetzee, D., Bedelu, M., van Cutsem, G. and Meintjes, G. (2007) Evaluation of a Diagnostic Algorithm for Smear-Negative Pulmonary Tuberculosis in HIV-Infected Adults. South African Medical Journal, 97, 517-523.

[33] Abaye, G.E., Abebe, T., Worku, A., Tolessa, D., Ameni, G. and Mihret, A. (2017) Detection of Mycobacterium tuberculosis from the Stool of HIV Sero-Positive Individuals Suspected of Pulmonary Tuberculosis. PLoS One, 12, e0177529. https://doi.org/10.1371/journal.pone.0177529

[34] Padmapriyadarsini, C., Tripathy, S., Sekar, L., Bhavani, P.K., Gaikwad, N., Annadurai, S., Narendran, G., Selvakumar, N., Risbud, A.R., Sheta, D., Rajasekaran, S., Thomas, A., Wares, F. and Swaminathan, S. (2013) Evaluation of a Diagnostic Algorithm for 
Sputum Smear-Negative Pulmonary Tuberculosis in HIV-Infected Adults. Journal of Acquired Immune Deficiency Syndromes, 63, 331-338. https://doi.org/10.1097/QAI.0b013e31829341af

[35] Walley, J., Kunutsor, S., Evans, M., Thoulass, J., Katabira, E., Muchuro, S. and Matovu, A. (2011) Validation in Uganda of the New WHO Diagnostic Algorithm for Smear-Negative Pulmonary Tuberculosis in HIV Prevalent Settings. Journal of Acquired Immune Deficiency Syndromes, 57, e93-e100. https://doi.org/10.1097/QAI.0b013e3182243a8c

[36] Kang, Y.A., Kwon, S.Y., Yoon, H.I., Lee, J.H. and Lee, C.T. (2009) Role of C-Reactive Protein and Procalcitonin in Differentiation of Tuberculosis from Bacterial Community Acquired Pneumonia. The Korean Journal of Internal Medicine, 24, 337-342. https://doi.org/10.3904/kjim.2009.24.4.337

[37] Yoon, N.B., Son, C. and Um, S.J. (2013) Role of the Neutrophil-Lymphocyte Count Ratio in the Differential Diagnosis between Pulmonary Tuberculosis and Bacterial Community-Acquired Pneumonia. Annals of Laboratory Medicine, 33, 105-110. https://doi.org/10.3343/alm.2013.33.2.105

[38] Baynes, R., Flax, H., Bothwell, T.H., et al. (1986a) Haematologicaland Iron Related Measurements in Active Pulmonary Tuberculosis. Scandinavian Journal of Haematology, 36, 280-287. https://doi.org/10.1111/j.1600-0609.1986.tb01735.x

[39] Corr Jr., W.P., Kyle, R. and Bowie, E.J. (1964) Hematologic Changes in Tuberculosis. The American Journal of the Medical Sciences, 248, 709-714. https://doi.org/10.1097/00000441-196412000-00012

[40] Cliff, J.M., Kaufmann, S.H., McShane, H., van Helden, P. and O'Garra, A. (2015) The Human Immune Response to Tuberculosis and Its Treatment: A View from the Blood. Immunological Reviews, 264, 88-102. https://doi.org/10.1111/imr.12269

[41] O'Garra, A., Redford, P.S., McNab, F.W., Bloom, C.I., Wilkinson, R.J. and Berry, M.P. (2013) The Immune Response in Tuberculosis. Annual Review of Immunology, 31, 475-527. https://doi.org/10.1146/annurev-immunol-032712-095939

[42] Basu Roy, R., Whittaker, E. and Kampmann, B. (2012) Current Understanding of the Immune Response to Tuberculosis in Children. Current Opinion in Infectious Diseases, 25, 250-257. https://doi.org/10.1097/QCO.0b013e3283529af9

[43] Madaleno, J., Fernandes, A., Cochicho, J., Silva, N. and Carvalho, A. (2016) Immune Thrombocytopenia Associated with Pleural and Pericardial Tuberculosis: Case Report. Revista Brasileira de Hematologia e Hemoterapia, 38, 163-165. https://doi.org/10.1016/j.bjhh.2016.02.002

[44] Garg, R., Gupta, V., Mehra, S., Singh, R. and Prasad, R. (2007) Rifampicin Induced Thrombocytopenia. Indian Journal of Tuberculosis, 54, 94-96.

[45] Yakar, F., Yildiz, N., Yakar, A. and Kılıçaslan, Z. (2013) Isoniazid- and Rifampicin-Induced Thrombocytopenia. Multidisciplinary Respiratory Medicine, 8, 13. https://doi.org/10.1186/2049-6958-8-13

[46] Renshaw, A.A. and Gould, E.W. (2013) Thrombocytosis Is Associated with Mycobacterium tuberculosis Infection and Positive Acid-Fast Stains in Granulomas. American Journal of Clinical Pathology, 139, 584-586. https://doi.org/10.1309/AJCPCM1CKASVBMBP

[47] Cho, S.Y., Lee, H.J., Kim, J.W. and Park, T.S. (2015) Mean Platelet Volume and Mean Platelet Volume/Platelet Count Ratio in Patients with Chronic Alcohol Consumption. Platelets, 26, 371-372. https://doi.org/10.3109/09537104.2014.887200

[48] Lee, M.Y., Kim, Y.J., Lee, H.J., Cho, S.Y. and Park, T.S. (2016) Mean Platelet Volume in Mycobacterium Tuberculosis Infection. BioMed Research International, 2016, Article ID: 7508763. https://doi.org/10.1155/2016/7508763 
[49] Ghare, S., Patil, M., Hote, P., Suttles, J., McClain, C., Barve, S. and Joshi-Barve, S. (2011) Ethanol Inhibits Lipid Raft-Mediated TCR Signaling and IL-2 Expression: Potential Mechanism of Alcohol-Induced Immune Suppression. Alcoholism: Clinical and Experimental Research, 35, 1435-1444. https://doi.org/10.1111/j.1530-0277.2011.01479.x

[50] Molina, P.E., Happel, K.I., Zhang, P., Kolls, J.K. and Nelson, S. (2010) Focus on: Alcohol and the Immune System. Alcohol Research \& Health, 33, 97-108 